\title{
GRAMATICALIZAÇÃO DA PREPOSIÇÃO NA FORMA REDUZIDA "PRA" COMO SOLUÇÃO DE ENUNCIADOS AMBÍGUOS
}

\section{ARTIGO ORIGINAL}

SEBASTIÃO, Hugo Mendes ${ }^{1}$

SEBASTIÃO, Hugo Mendes. Gramaticalização da preposição na forma reduzida "Pra" como solução de enunciados ambíguos. Revista Científica Multidisciplinar Núcleo do Conhecimento. Ano. 06, Ed. 12, Vol. 06, pp. 189-198. Dezembro de 2021. ISSN: 2448-0959,

Link de acesso: https://www.nucleodoconhecimento.com.br/letras/gramaticalizacao-dapreposicao

\section{RESUMO}

O intuito principal deste trabalho é perceber e analisar a ocorrência da ambiguidade proporcionada pela homografia e homofonia da preposição "para" e da forma verbal "para" que ocorrem em alguns enunciados e também identificar uma possível solução, dentro do próprio dinamismo evolucional da língua, para essa questão. Com esse propósito partimos do seguinte pressuposto: Poderia a forma gramaticalizada da preposição "pra" ser uma solução para tais equívocos? Para tanto, cotejamos alguns enunciados em que as duas palavras aparecem e causam ambiguidades. Em seguida, foi proposta reescrita dos enunciados, no entanto, trocando a preposição "para" pôr sua forma gramaticalizada "pra". Com isso constatamos que a forma gramaticalizada é um artifício para a solução das possíveis confusões semânticas.

Palavras-Chave: Gramaticalização, Pancrônica, Forma Verbal, Preposição.

\footnotetext{
${ }^{1}$ Mestrado em Linguística, pós-graduado em Ensino de redação, Língua Portuguesa e Literatura, pós-graduado em Ensino de Língua Inglesa, graduado em Letras Português e Inglês, graduado em Pedagogia. ORCID: https://orcid.org/0000-00024867-9724
} 


\section{INTRODUÇÃO}

É um conhecimento amplamente disseminado que muitos foram os fatores responsáveis pelo desenvolvimento da civilização humana, dentre eles podemos destacar um que foi primordial para a perpetuação dos seres humanos como indivíduos sociais e capazes de transferir conhecimento para as gerações futuras: a linguagem. Por sua vez o aspecto de linguagem pode causar certa confusão a princípio, pois existem várias maneiras possíveis de se utilizar a linguagem para se estabelecer a comunicação, desde imagens e sons a gestos corporais. Sendo assim, alguns pontos precisam ser esclarecidos.

Para o escopo deste trabalho, seguimos a vertente de comunicação que se envereda pelos estudos de Saussure (2006), os quais entendem a linguagem como um conjunto de regras complexas e organizadas que podem utilizar vários meios para estabelecer comunicação: imagens, signos e sons produzidos pelo aparelho fonador. No entanto, o espectro que abrange toda a gama de pontos que compõem a premissa de uma linguagem organizada e funcional é muito amplo, logo delimitações precisam ser delineadas e certas nomenclaturas estabelecidas.

Então a partir deste ponto trataremos a concepção de linguagem por uma das partes que a constituem: a linguagem verbal. Tendo como base os estudos desenvolvidos por Saussure (2006), conceituamos a linguagem verbal como algo manifestado por meio da escrita ou da conversação entre dois ou mais participantes que se apropriam de um código comum para comunicar-se. Código esse que quando organizado e guiado por regras claras e pré-estabelecidas pode ser percebido como uma língua.

Apreciado o espectro de linguagem a ser trabalhado e também percebido que a evolução humana e o desenvolvimento de uma linguagem organizada e consciente estão estreitamente ligados, escolhemos alguns pontos que demonstram os desdobramentos pancrônicos[2] presentes em uma língua (no caso do nosso trabalho a Língua Portuguesa), mostrando, assim, que tanto o dinamismo social quanto o comunicativo estão imbricados. 
Como procedimento teórico-metodológico, optamos a favor dos ontos levantados pelos estudos da Gramaticalização, mais especificamente aos que se remetem às questões da passagem das palavras lexicais para as gramaticais.

(...) fazem a distinção entre itens lexicais, signos linguísticos plenos, classes abertas de palavras, lexemas concretos, palavras principais, de um lado, e itens gramaticais, signos linguísticos "vazios", classes fechadas de palavras, lexemas abstratos, palavras acessórias, do outro;

(ii) consideram que as últimas categorias tendem a se originar das primeiras. (GONÇALVES et al., 2007, p. 19)

Ao traçarmos um paralelo entre as palavras lexicais e as gramaticais, somos capazes de demonstrar como a relação de palavras homófonas e homógrafas, em classes gramaticais diferentes, estão relacionada às mudanças sincrônicas e diacrônicas de uma língua.

Outra questão passível de análise são os pontos que promovem a erosão fonética/redução fonológica que acometem algumas palavras no decorrer do desenvolvimento de uma língua e como isso é responsável por mudanças de pronúncia e de sentido. De acordo com Gonçalves et al. (2007, p. 34), entendemos esse processo linguístico como:

(...) toda a justificativa que lhe dá sustentação como um estágio muito adiantado de gramaticalização revela uma argumentação circular: uma forma-fonte perde traços semânticos rumo a um conceito mais abstrato, como o das relações gramaticais, porque perde material fonológico.

Também demonstramos como os processos anteriormente citados nos ajudam a entender a trajetória de transformação da preposição "para" em "pra" e como isso auxilia a responder principal questão deste trabalho: Poderia a forma gramaticalizada da preposição "pra" ser uma solução para enunciados semelhantes em que as duas proposições podem ser usadas?

Para tanto, como o corpus de análise, utilizamos excertos fictícios de alguns enunciados que (apesar de serem criados para a análise propriamente dita) poderiam facilmente ser empregados em situações reais. Nesses excertos analisamos de forma 
pontual a preposição "para" e também a forma verbal "para" (a qual assume essa forma quando conjugado na terceira pessoa do presente do modo indicativo), cujo acento gráfico foi removido devido a última reforma ortográfica. Posteriormente, apresentamos como a forma gramaticalizada "pra" (preposição) pode ser um ótimo recurso para solução de confusões semânticas entre enunciados nos quais são possíveis o uso das duas formas.

\section{A GRAMATICALIZAÇÃO COMO PROCESSO DE ANÁlisE PANCRÔNICA NA LÍNGUA}

Antes de qualquer reflexão ou análise, a ideia que se projeta sobre o conceito de gramaticalização não pode ser esvaziada a tal ponto que se confunda com a definição de gramática. Pois apesar de ambas fazerem parte de um mesmo universo linguístico (a gramática prescrevendo o uso da língua e a gramaticalização discorrendo sobre a evolução da língua), cada uma delas possui postulados teóricos distintos. Enxergar as nuances entre elas não é algo tão simples, porque mesmo embora com campos teóricos diferenciados e delimitados, muitas vezes tanto os estudos levantados pela teoria gramatical quanto as observações levantadas pelos paradigmas da gramaticalização fornecem conteúdo para que uma se baseie na outra para exemplificação e construção de suas teorias.

Outro item que devemos discutir é a percepção da gramaticalização como teoria ou como conjunto de critérios definidos no interior de outras disciplinas.

Apesar de preencher todos os requisitos para ser classificada como uma teoria, alguns detratores colocam a gramaticalização no patamar de partes componentes de outras correntes teóricas; isso ocorre porque eles afirmam que os métodos de observação presentes nela não são claros. Porém não partilhamos dessa perspectiva.

Acreditamos que as verificações levantadas pela teoria da gramaticalização mostram claramente os desdobramentos evolutivos intrínsecos a uma língua, justamente nos pontos que tangem as mudanças nos níveis fonológico, morfológico, sintático, semântico e discursivo. Embora, esses pontos não precisam ocorrer simultaneamente 
para caracterizá-la como teoria, na maioria das vezes temos dois ou mais deles envolvidos.

Relativamente aos mecanismos da gramaticalização, no processo de
mudança não há nada de determinístico, ou seja, não é necessária a
implementação de todos esses mecanismos para que uma mudança
seja identificada como gramaticalização, fato bastante enfatizado
pelos seus estudiosos, mas que parece ignorado pelos seus
detratores. Newmeye (2001,196-202), por exemplo, a certa altura de
seu artigo, fornece, como parecendo um questionamento novo,
evidências de que as partes componentes da gramaticalização podem
ocorrer independentemente uma da outra. (GONÇALVES et al. 2007,
p.58,59)

Em relação ao nosso artigo, as análises situam-se entre os níveis morfológico, sintático e semântico.

Para o nível morfológico, os postulados sobre a redução fonológica demonstram como a preposição "para" perdeu material fonético com o passar do tempo, assumindo, assim, a forma mais usualmente encontrada na fala: "pra". Isso é feito juntamente com a observação da preposição "para" em relação à forma verbal "para" (terceira pessoa do singular do indicativo do presente), em que observamos as relações gramaticais e lexicais nessas duas palavras, tendo a preposição como uma palavra gramatical (com menos sentido próprio) e a forma verbal como uma palavra lexical (com mais sentido próprio no nível da oração).

Segundo Gonçalves et al. (2007, p.34):

Principalmente nos casos de morfologização, a redução fonológica parece atuar sobre a forma em gramaticalização para ajustá-la ao domínio dos itens gramaticais, cuja grande maioria apresenta pouca substância fonética, por conta do "pouco" conteúdo de expressão. Mantêm-se, assim, as relações icônicas da língua, atendendo-se ao princípio da quantidade, que dita que o tamanho de um item linguístico é proporcional à quantidade de informações que ele codifica.

Logo, ao testarmos as relações gramaticais e lexicais entre as homógrafas "para" (preposição) e "para" (forma verbal) com acréscimo da evolução da palavra "pra", conseguimos explicar a condução pancrônica do processo. 


\section{ACENTOS DIFERENCIAIS: ACORDO ORTOGRÁFICO BRASILEIRO}

Dentro do extenso vocabulário da nossa língua portuguesa, nós temos muitas palavras que possuem grafia e pronúncia parecidas e a esse fenômeno são atribuídos os nomes de homofonia e homografia. Para evitar que haja confusões entre o uso dessas palavras, a língua utiliza-se de alguns recursos para promover diferenças entre os vocábulos que são parecidos, dentre esses recursos, podemos citar os acentos gráficos, os quais promovem as diferenças no que se remete à prosódia e à ortoepia. Na gramática normativa conhecemos esses sinais gráficos como acentos diferenciais.

Com o novo acordo ortográfico que entrou em vigor no ano de 2016 algumas palavras sofreram alteração em relação aos acentos diferenciais. Conforme Trufano (2008) o acento que diferenciava os pares "pára/para, péla(s)/pela(s), pêlo(s)/pelo(s), pólo(s)/polo(s) e pêra/pera" não é mais usados.

O intuito principal desse acordo é padronizar o uso da língua portuguesa nos países lusófonos, evitando, assim, possíveis confusões entre falantes da língua portuguesa, mesmo que eles sejam de países diferentes. No entanto, a retirada desses acentos pode causar, até mesmo, confusões no uso da língua entre os falantes de um mesmo país. Principalmente no tocante à preposição "para" e ao verbo "para" quando conjugado na terceira pessoa do presente do indicativo, pois ao analisarmos a perda do acento diferencial no verbo, fica evidente a possível confusão entre a preposição e o verbo.

Essa confusão pode ser sanada por meio da contextualização do enunciado que se utiliza de tais palavras, entretanto, em um recorte menor, a confusão entre a ideia de movimento da preposição e a ideia de ação do verbo pode gerar certa ambiguidade na interpretação de alguns textos.

Todavia, a mesma evolução da língua que gerou esse possível engano também pode proporcionar a solução para este problema. Isso porque podemos perceber que alguns enunciados fazem uso de uma variante da proposição "para" que aparece de uma forma reduzida com pronúncia e escrita própria: "pra". Embora essa forma não 
esteja incorporada à norma padrão da língua, o seu uso é bem recorrente, principalmente na modalidade falada e na modalidade informal escrita da língua.

Sendo assim, uma possível dicionarização da forma gramaticalizada dessa preposição seria uma boa maneira de evitar interpretações ambíguas dos enunciados.

\section{ANÁLISE CONTRASTIVA E COMPARATIVA ENTRE A PREPOSIÇÃO "PARA" E A FORMA VERBAL "PARA"}

Os postulados dos estudos da teoria da gramaticalização são de suma importância para explicitar a trajetória da preposição "para" desde o último acordo ortográfico até os dias atuais, mais especificamente os pontos que abordam a erosão fonética em nível morfológico, no qual é observável o surgimento da forma reduzida da preposição e também os que traçam a comparação entre a preposição como palavra gramatical e a forma verbal como palavra lexical.

Antes de iniciarmos a nossa análise, vamos observar o que (GONÇALVES et al., 2007, p. 15) coloca como o processo de gramaticalização:

Dentre os vários processos de mudança linguística, a gramaticalização é considerada um dos mais comuns que se tem observado nas línguas em geral. A constante renovação do sistema linguístico percebida, sobretudo, pelo surgimento de novas funções para formas já existentes e de novas formas para funções já existentes - traz à tona a noção de "gramática emergente", concepção assumida de modo explícito ou não por vários estudiosos da gramaticalização.

Logo, podemos conceber a gramaticalização como um movimento contínuo dentro da língua, em que o dinamismo de uso gera novas possibilidades de escrita, sentido e pronúncia, o qual acontece, de certa forma, naturalmente.

Também é válido destacar a diferença que se atribui entre as palavras lexicais e gramaticais. Em (GONÇALVES et al., 2007, p. 20), podemos observar a seguinte definição:

(...) com a acepção mais clássica de gramaticalização, palavras de uma categoria lexical plena (nomes, verbos e adjetivos) podem passar a integrar a classe das categorias gramaticais (preposições, 
advérbios, auxiliares etc.), as quais, em momento posterior, podem vir até mesmo a se tornar afixos.

Tendo isso em vista, começamos nossa análise pelo seguinte enunciado:

Exemplo 1: "Trânsito pesado "para" a rodovia marginal".

Ao lermos tal enunciado sem um contexto maior, a ambiguidade está instaurada, pois podemos tanto ter a ideia de movimento para a rodovia marginal (preposição) quanto a ideia de que o trânsito impede o fluxo na rodovia (forma verbal). O que não aconteceria com a utilização do verbo em sua forma anterior ao último acordo ortográfico:

"Trânsito pesado "para" a rodovia marginal".

Também podemos observar o mesmo processo nesta oração:

Exemplo 2: "Xingamento "para" o menino da primeira fila". / Xingamento "para" o menino da primeira fila".

Em ambos os casos, é possível perceber que a retirada do acento diferencial entre as duas palavras causou confusão por conta da pronúncia e da escrita das duas palavras.

No entanto, ao constatarmos que a preposição "para" vem sofrendo um processo evolutivo de escrita e pronúncia, em que ela passa a assumir a forma "pra", o problema de ambiguidade estaria resolvido. Podemos notar isso ao aplicar a forma gramaticalizada da preposição no exemplo 1.

Exemplo 3: "Trânsito pesado "pra" rodovia marginal".

A gramaticalização da preposição, mais especificamente o processo de erosão fonética, cria uma forma própria e livre de ambiguidades.

Outro aspecto que devemos observar no exemplo 3 é a elisão da preposição com o artigo definido "a". Nesse caso, não há possibilidade de aplicarmos o artigo separadamente, pois isso causaria cacofonia. 
Isso fica mais evidente ao aplicarmos a preposição gramaticalizada no segundo exemplo:

Exemplo 4: Xingamento "pro" menino da primeira fila".

No exemplo 4 a elisão é mais explícita, pois podemos ver claramente a junção da preposição reduzida com o artigo definido $o$, tornando mais cognoscível a perda de material escrito e fonológico da preposição.

A questão do lexical e do gramatical também pode ser observada, isso porque temos uma palavra gramatical que assume uma forma mais gramatical ainda.

Conforme Gonçalves et al. (2007) uma forma pode perder material fonológico rumo a conceitos mais abstratos, ou seja, a trajetória da gramaticalização segue o fluxo em que uma forma lexical assume uma forma gramatical, ou uma forma gramatical assume uma forma mais gramatical ainda. Justamente o que presenciamos na redução da preposição "para" que assume a forma "pra".

Sendo assim, acreditamos que uma futura dicionarização da preposição reduzida "pra", poderia evitar ambiguidades na interpretação de enunciados semelhantes aos que utilizamos em nossa análise.

\section{CONSIDERAÇÕES FINAIS}

As análises contrastivas e comparativas levantadas nesta pesquisa tiveram como objetivo investigar as possibilidades de interpretações ambíguas em enunciados semelhantes em que haja a forma verba "para" e a preposição "para". Nesses enunciados a grafia e a pronúncia do verbo e da preposição são idênticas, o que ocasiona duas possibilidades semânticas: a ideia de ação do verbo ou a ideia de direção da preposição. Vimos que isso ocorreu após o último acordo ortográfico que entrou em vigor em 2016, em que o acento diferencial do verbo foi retirado.

O levamento teórico juntamente à análise prática conseguiu satisfazer o principal questionamento para esse trabalho: Poderia a forma gramaticalizada da preposição 
"pra" ser uma solução para interpretações ambíguas entre enunciados em que estão presentes o verbo e a preposição?

Sendo assim, constatamos que o processo de gramaticalização que ocorre em relação à preposição modificando-a na forma reduzida "pra" apresenta soluções concretas para a solução dessas ambiguidades. Esse processo que segundo Gonçalves et al. (2007) é descrito como erosão fonética/redução linguística cria uma forma que apresenta pronúncia e escrita própria, logo evitando qualquer possível confusão entre as duas formas.

Similarmente, observamos o processo que define realmente o conceito da teoria da gramaticalização: a passagem de uma forma lexical para uma forma gramatical, ou a passagem de uma forma gramatical para uma mais gramatical. Isso fica claro ao percebemos a passagem da forma gramatical "para" para uma mais gramatical "pra".

Não tivemos como intuito esgotar as possibilidades de pesquisa com este artigo, isso porque entendemos a profusão contida nos estudos da teoria da gramaticalização e de como eles são úteis para as discussões sobre as evoluções dentro de uma língua.

\section{REFERÊNCIAS}

BECHARA, E. Moderna Gramática Portuguesa. Rio de Janeiro: Lucerda, 2003.

CASTILHO, A. T. Reflexões sobre a gramaticalização. Seminário de Estudos Luso-Brasileiros, Universidade de Münster, 2003.

GONÇALVES, S. C. L. et al. Introdução a gramaticalização: princípios teóricos e aplicação; São Paulo: Parábola Editorial, 2007.

MIOTO, C.; SILVA, M. C. F.; LOPES, R. E. V. Novo Manual de Sintaxe. Florianópolis: Insular, $3^{\mathrm{a}}$ ed., 2007.

ORLANDI, E.P. Duas obras, um Saussure e nenhuma publicação: 0 que é lingüística. São Paulo: Ed. Brasiliense. Coleção Primeiros Passos, 2009. 
POSSENTI, S. Por que (não) ensinar gramática na escola. Campinas, SP: Mercado de Letras, Associação de Leitura do Brasil, 1996.

SAUSSURE, F. Curso de Lingüística Geral. São Paulo: Cultrix, 2006.

TRUFANO, D. Guia Prático da Nova Ortogtafia: Saiba o que mudou na ortografia brasileira, $1^{\circ}$ ed. São Paulo: Editora Melhoramentos, 2008.

\section{APÊNDICE - REFERÊNCIA NOTA DE RODAPÉ}

2. Termo que se refere ao que é diacrônico e sincrônico.

Enviado: Junho, 2021.

Aprovado: Dezembro, 2021. 